Open

\title{
A Pooled Analysis of Infections, Malignancy, and Mortality in Infliximab- and Immunomodulator-Treated Adult Patients With Inflammatory Bowel Disease
}

Gary R. Lichtenstein, MD¹, Paul Rutgeerts, MD, PhD², William J. Sandborn, MD³, Bruce E. Sands, MD4, Robert H. Diamond, MD5, Marion Blank, $\mathrm{PhD}^{5}$, Jennifer Montello, BA ${ }^{5}$, Linda Tang, PhD ${ }^{5}$, Freddy Cornillie, $\mathrm{PhD}^{6}$ and Jean-Frédéric Colombel, MD ${ }^{7}$

OBJECTIVES: The objective of this study was to analyze the safety of long-term infliximab treatment, with/without concomitant immunomodulators, across Crohn's disease (CD) and ulcerative colitis (UC) clinical trials.

METHODS: $\quad$ To maximize sample size, we pooled primary safety data across $10 \mathrm{CD}$ or UC trials, including five randomized, controlled trials contributing data from patients who received intravenous infliximab 5 or $10 \mathrm{mg} / \mathrm{kg}$ ( $n=1,713$; \pm azathioprine) or placebo ( $n=406$; \pm azathioprine). Pooled incidences and $95 \%$ confidence intervals (Cls) were determined for mortality, infection, and malignancy. Standardized incidence ratios and $95 \% \mathrm{Cls}$ were also determined for malignancies using the Surveillance, Epidemiology, and End Results database.

RESULTS: $\quad$ We observed no increase in infections, serious infections, or malignancy with infliximab vs. placebo in these patients with inflammatory bowel disease (IBD). In patients with UC, but not CD, immunomodulator treatment (vs. treatment without immunomodulator) yielded a higher incidence $(95 \% \mathrm{Cl})$ of infections $(120.07(110.66,130.08) / 100$ patient-years (pt-yrs) vs. $92.47(84.54,100.94) / 100$ pt-yrs). Among placebo-treated patients with CD, but not UC, those with immunomodulator use demonstrated a higher incidence $(95 \% \mathrm{Cl})$ of malignancy vs. no immunomodulator treatment $(1.84(0.22,6.66) / 100$ pt-yrs vs. $0.00(0.00,0.00) / 100$ pt-yrs $)$. Mortality and infection-related mortality appeared unaffected by infliximab or immunomodulator treatment.

CONCLUSIONS: Infliximab treatment of IBD did not appear to affect incidences of infection, mortality, or malignancy. Relative to patients with no immunomodulator use, immunomodulator-treated UC patients demonstrated a higher incidence of infection and immunomodulator-plus-placebo-treated CD patients demonstrated a higher incidence of malignancy.

Am J Gastroenterol 2012; 107:1051-1063; doi:10.1038/ajg.2012.89; published online 22 May 2012

\section{INTRODUCTION}

Inflammatory bowel disease (IBD) is a chronic, inflammatory disorder of the gastrointestinal tract. As such, standard therapies for IBD have focused on nonspecific inhibition of inflammation with sulfasalazine, mesalazine, steroids, the thiopurines azathioprine (AZA) and 6-mercaptopurine (6-MP), and methotrexate (MTX) (1). While these agents can be moderately effective in maintaining corticosteroid-induced remission, relapse can be common $(2,3)$. In addition, thiopurine therapy of IBD carries an increased risk of lymphoproliferative disorders (4).
On the basis of the unmet need for patients intolerant of or unresponsive to standard therapy, several antagonists of the proinflammatory cytokine tumor necrosis factor (TNF) have been developed, including adalimumab, etanercept, infliximab, and certolizumab pegol. Although TNF antagonist therapy is generally well tolerated by patients with IBD, a unique spectrum of safety issues related to blocking TNF, including life-threatening and opportunistic infection, malignancy, and mortality, must be considered. While researchers have attempted to obtain consensus on the relationship between TNF antagonist therapy and

'Division of Gastroenterology, Hospital of The University of Pennsylvania, University of Pennsylvania School of Medicine, Philadelphia, Pennsylvania, USA; ${ }^{2}$ University Department of Internal Medicine, Hospital Gasthuisberg, Leuven, Belgium; ${ }^{3}$ Division of Gastroenterology, University of California San Diego, La Jolla, California, USA; ${ }^{2}$ Division of Gastroenterology, Mount Sinai School of Medicine, New York, New York, USA; 5 Janssen Research \& Development, Spring House, Pennsylvania, USA; ${ }^{6}$ Janssen Biologics BV, Heverlee, Belgium; ${ }^{7}$ Hopital Claude Huriez, Centre Hospitalier et Universitaire de Lille, Lille, France. Correspondence: Gary R. Lichtenstein, MD, Department of Medicine, Division of Gastroenterology, Gl Administration Offices, 9th Floor Penn Tower, One Convention Avenue, Philadelphia, Pennsylvania 19104-4283, USA. E-mail: gr|@uphs.upenn.edu

Received 11 October 2011; accepted 6 March 2012 
these relatively rare events, analyses have generally been limited by comparatively small study populations and short periods of patient follow-up.

The TNF antagonist infliximab has been used to treat patients with moderately-to-severely active IBD for more than a decade. As infliximab was approved for the treatment of moderate-tosevere Crohn's disease (CD), the sponsor has conducted several large, randomized, controlled phase 3 clinical trials of infliximab maintenance therapy in IBD (hereafter referred to as "pivotal phase 3 trials"), including the ACCENT I (5,6), ACCENT II (7), and SONIC (8) trials in CD and the ACT 1 and ACT 2 trials (9) that formed the basis for approval of infliximab in ulcerative colitis (UC).

Although safety findings related to each of these studies have been reported in separate publications, a pooled analysis of key safety outcomes has been recently conducted for all sponsor-initiated infliximab trials in IBD, with emphasis on the five pivotal phase 3 trials that contribute nearly $90 \%$ of the data for patients in the pooled IBD safety analyses. Given the continued need for safety data related to TNF antagonism, findings of these analyses are detailed herein.

\section{METHODS}

The 10 (7 CD, 3 UC) clinical trials included in these pooled analyses represent the totality of the sponsor's clinical safety database for infliximab in the treatment of adult patients with IBD. The pooled studies comprise five smaller trials ( $4 \mathrm{CD}, 1 \mathrm{UC}$ ) evaluating a total of 244 patients (10-15), 22 of whom contributed data to more than one treatment group per study, and five pivotal phase 3 trials evaluating infliximab maintenance therapy in 1,644 patients with CD (5-8) and 741 patients with UC (9), 184 of whom contributed data to more than one treatment group per study (Tables 1-5).

The five pivotal phase 3 trials, i.e., ACCENT I, ACCENT II, SONIC, ACT 1, and ACT 2, contributed approximately $89 \%$ $(2,119 / 2,385)$ of all patients with data in the overall pooled analyses and were generally consistent in terms of study designs, in that they were all randomized, multicenter, double-blind trials that included a control group (Table 1). Note that for four of the five pivotal phase 3 trials (ACCENT I, ACCENT II, ACT 1, and ACT 2), treatment with the immunomodulators AZA, 6-MP, and MTX or with corticosteroids was allowed during study participation, but such use was not a randomized study treatment. Each of these study protocols stipulated that patients would continue a stable regimen of baseline immunomodulator therapy throughout study participation. Conversely, the SONIC trial enrolled exclusively immunomodulator-naïve patients, and these patients were randomized to receive AZA, $5 \mathrm{mg} / \mathrm{kg}$ of infliximab, or AZA plus $5 \mathrm{mg} /$ $\mathrm{kg}$ of infliximab (8).

All study protocols were approved by the institutional review board at each participating site, and all patients provided written informed consent before beginning study participation. Janssen Biotech, Inc. (Horsham, PA) provided infliximab, active comparator (AZA in the SONIC trial), and placebo (as appropriate) for intravenous infusion.
To evaluate the occurrence of uncommon events, safety data from the seven studies in $\mathrm{CD}$ (with the majority of the data coming from the pivotal ACCENT I, ACCENT II, and SONIC studies) were pooled and are reported as 'CD studies'. When pooled with data from the three 'UC studies' (with the majority of the data deriving from the pivotal ACT 1 and ACT 2 studies), they are reported as 'IBD studies'. Safety data from the pivotal phase 3 trials in IBD, i.e., ACCENT I, ACCENT II, SONIC, ACT 1, and $\mathrm{ACT} 2$, were also separately pooled across the three $\mathrm{CD}$, two UC, and all five pivotal phase 3 IBD studies. Summaries of key design features of these studies are provided in Table 1.

The incidences of adverse events per 100 patient-years (pt-yrs) of follow-up were calculated for infections, malignancies (including both solid tumors and hematological malignancies and excluding nonmelanoma skin cancers) and deaths by treatment group (infliximab vs. placebo) and also by immunomodulator use (treatment vs. no treatment) for infections and malignancies as the quotient of the total number of events and pt-yrs of follow-up multiplied by 100 ; exact $95 \%$ confidence intervals (CIs) were also calculated.

For malignancies (excluding nonmelanoma skin cancer), standardized incidence ratios (SIRs) were also calculated as the quotient of the observed and expected numbers of patients with malignancy; 95\% CIs were determined using exact methodology. The expected numbers of malignancy were derived using data adjusted for age, sex, and race from the general US population in the Surveillance, Epidemiology, and End Results (SEER) database (16).

Fisher's exact test was used to compare the proportions of patients who experienced an adverse event of interest (e.g., infection, malignancy, or death) between treatment groups. Because a large number of safety parameters were evaluated, the Fisher's exact test is employed not for hypothesis testing but rather as an aid in signal detection to highlight differences requiring closer examination.

All patients in ACCENT I and ACCENT II received infliximab $5 \mathrm{mg} / \mathrm{kg}$ at week 0 and were therefore counted in the infliximab column in the calculation of pt-yrs of follow-up. Pt-yrs of follow-up for placebo were determined for the 161 placebo plus AZA-treated CD patients in the SONIC study plus additional placebo-treated patients from other CD studies (T08, T11, T16, and T20; see Table 1) as applicable to the subpopulation being assessed. Note that infliximab use, both in combination with immunomodulators and alone, and immunomodulator use, both in combination with infliximab and alone, are pooled in these analyses such that infliximab use refers to any use of infliximab and immunomodulator use refers to any use of immunomodulators. Also note that the placebo group includes only patients who never received infliximab.

As noted above, infliximab treatment was generally randomized and blinded, while immunomodulator treatment, with the exception of the SONIC trial, reflects immunomodulator use at baseline, i.e., immunomodulator use was not randomized or blinded and assumes that such use continued during the study. Protocols for these four of five pivotal phase 3 trials mandated that patients receiving a stable immunomodulator regimen at baseline would continue such use throughout study participation. 
Table 1. Key features of 10 sponsor-initiated studies of infliximab in IBD

\begin{tabular}{|c|c|c|c|c|}
\hline Study (reference) & Pt. population & Study design & $\begin{array}{l}\text { Treatment regimens } \\
\text { (no. of pts. evaluated) }\end{array}$ & $\begin{array}{l}\text { AE reporting } \\
\text { period (wks) }\end{array}$ \\
\hline \multicolumn{5}{|c|}{ Smaller trials of infliximab in IBD } \\
\hline С0168T08 (15) & $\begin{array}{l}\text { Severe } C D(C D A I>150) \\
\text { refractory to corticosteroid } \\
\text { therapy }\end{array}$ & Phase $1, \mathrm{SC}, \mathrm{OL}$, single dose & Grp 2: Infliximab $20 \mathrm{mg} / \mathrm{kg}(n=2)$ & 8 \\
\hline \multirow[t]{3}{*}{ C0168T11 (10) } & \multirow[t]{3}{*}{ Moderate-to-severe $\mathrm{CD}$} & \multirow[t]{3}{*}{$\begin{array}{l}\text { Phase 2, MC, OL, single dose, } \\
\text { sequential dose-escalating trial }\end{array}$} & Grp 1: Infliximab 1 mg/kg $(n=5)$ & \multirow[t]{3}{*}{12} \\
\hline & & & Grp 3: Infliximab 10 mg/kg $(n=5)$ & \\
\hline & & & Grp 4: Infliximab 20 mg/kg $(n=6)$ & \\
\hline \multirow[t]{6}{*}{ C0168T16 $(10,12,14)$} & \multirow[t]{6}{*}{ Moderate-to-severe $\mathrm{CD}$} & \multirow{6}{*}{$\begin{array}{l}\text { Phase } 2 / 3, \mathrm{MC}, \mathrm{DB}, \mathrm{PC} \text {, with } \\
\text { initial dose-ranging treatment } \\
\text { phase followed by repeated- } \\
\text { treatment phase plus OL treat- } \\
\text { ment for safety assessments }\end{array}$} & $\begin{array}{l}\text { Initial dose-ranging phase } \\
\text { (single dose) }\end{array}$ & \multirow[t]{6}{*}{$\begin{array}{l}16(n=35) \text { and } \\
48(n=73)\end{array}$} \\
\hline & & & Grp 4: Infliximab $20 \mathrm{mg} / \mathrm{kg}(n=28)$ & \\
\hline & & & $\begin{array}{l}\text { Open-label phase: Infliximab } 10 \mathrm{mg} / \mathrm{kg} \\
(n=48)\end{array}$ & \\
\hline & & & $\begin{array}{l}\text { Repeated-treatment phase } \\
\text { (4DB infusions) }\end{array}$ & \\
\hline & & & $\begin{array}{l}\text { Grp 1: Infliximab } 10 \mathrm{mg} / \mathrm{kg} \text { q8wks } \\
(n=37)\end{array}$ & \\
\hline & & & Grp 2: Placebo q8wks ( $n=36)$ & \\
\hline C0168T20 (11) & Fistulizing CD & $\begin{array}{l}\mathrm{MC}, \mathrm{DB}, \mathrm{PC} \text {, randomized } \\
\text { phase } 3 \text { trial }\end{array}$ & $\begin{array}{l}\text { Grp 1: Infliximab } 10 \mathrm{mg} / \mathrm{kg} \text { at wks } 0,2 \text {, } \\
6(n=32)\end{array}$ & 52 \\
\hline \multirow{2}{*}{ C0168T12 (13) } & \multirow{2}{*}{$\begin{array}{l}\text { Active UC (modified Truelove } \\
\text { and Witts score }>10 \text { ) }\end{array}$} & \multirow{2}{*}{$\begin{array}{l}\mathrm{MC}, \mathrm{DB}, \mathrm{PC} \text {, randomized } \\
\text { phase } 2 \text { trial }\end{array}$} & Grp 3: Infliximab $10 \mathrm{mg} / \mathrm{kg}(n=3)$ & \multirow{2}{*}{12} \\
\hline & & & Grp 4: Infliximab 20 mg/kg ( $n=2)$ & \\
\hline \multicolumn{5}{|c|}{ Pivotal phase 3 trials of infliximab in IBD } \\
\hline \multirow[t]{4}{*}{ ACCENT I $(5,6)$} & \multirow[t]{4}{*}{ Moderate-to-severe $\mathrm{CD}$} & $\begin{array}{l}\mathrm{MC}, \mathrm{DB}, \mathrm{PC} \text {, phase } 3 \\
\text { randomized trial }\end{array}$ & $\begin{array}{l}\text { All pts.: Infliximab } 5 \mathrm{mg} / \mathrm{kg} \text { at wk } 0 \\
(n=573)\end{array}$ & \multirow[t]{4}{*}{54} \\
\hline & & \multirow{3}{*}{$\begin{array}{l}\text { AZA, 6-MP, MTX, corticosteroids } \\
\text { allowed but not randomized } \\
\text { treatments }\end{array}$} & $\begin{array}{l}\text { Grp 1: Placebo at wks } 2,6 \text {, and q8wks } \\
\text { through wk } 46(n=188)\end{array}$ & \\
\hline & & & $\begin{array}{l}\text { Grp 2: Infliximab } 5 \mathrm{mg} / \mathrm{kg} \text { at wks 2, } 6 \text {, } \\
\text { and q8wks through wk } 46(n=192)\end{array}$ & \\
\hline & & & $\begin{array}{l}\text { Grp 3: Infliximab } 5 \mathrm{mg} / \mathrm{kg} \text { at wks } 2 \text { and } \\
6 \text {, then } 10 \mathrm{mg} / \mathrm{kg} \text { q8wks through wk } 46 \\
(n=193)\end{array}$ & \\
\hline \multirow[t]{2}{*}{ ACCENT ॥ (7) } & \multirow[t]{2}{*}{ Fistulizing CD } & $\begin{array}{l}\mathrm{MC}, \mathrm{DB}, \mathrm{PC} \text {, phase } 3 \\
\text { randomized trial }\end{array}$ & $\begin{array}{l}\text { All pts.: Infliximab } 5 \mathrm{mg} / \mathrm{kg} \text { at wks } 0,2 \text {, } \\
6(n=306)\end{array}$ & \multirow[t]{2}{*}{54} \\
\hline & & $\begin{array}{l}\text { AZA, 6-MP, MTX, corticosteroids } \\
\text { allowed but not randomized } \\
\text { treatments }\end{array}$ & $\begin{array}{l}\text { Grp 1: Placebo at wk } 14 \text { and } \\
\text { q8wks through wk } 46 \text { (crossover } \\
\text { to } 5 \mathrm{mg} / \mathrm{kg} \text { possible; } n=143 \text { for } \\
\text { placebo maintenance) }\end{array}$ & \\
\hline
\end{tabular}


Table 1. Continued

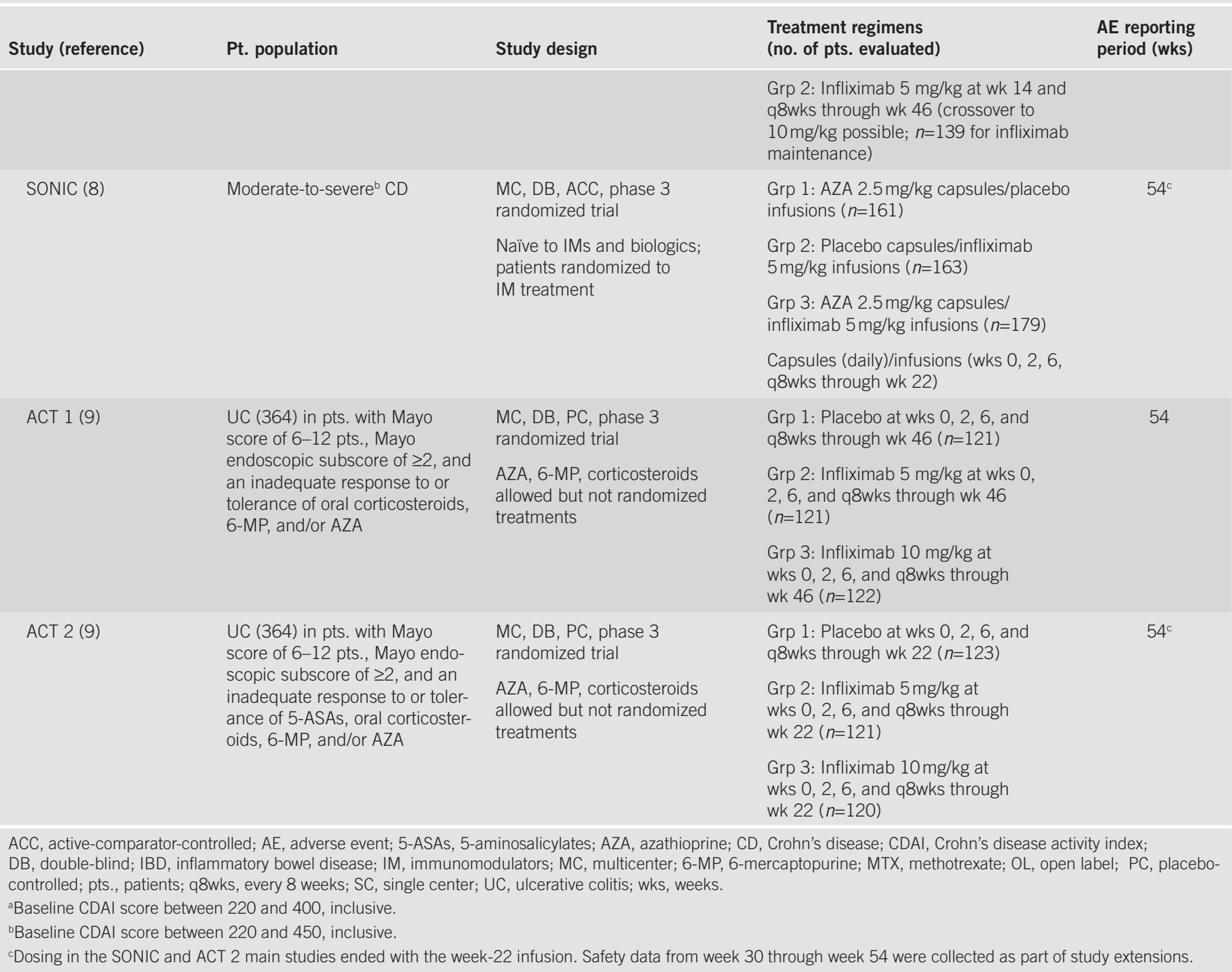

\section{RESULTS}

\section{Analysis groups and extent of exposure}

Across the 10 sponsor-initiated infliximab trials in IBD (five smaller studies and five pivotal phase 3 studies conducted following infliximab's initial approval), safety data for 2,385 patients were available for pooled safety analyses (see Tables 3-5). Note that some patients presented in Tables 1 and $\mathbf{2}$ contributed data to more than one treatment group in the analyses presented in Tables 3-5, e.g., 22 of the 244 patients in the five smaller studies and 33 of the 2,086 patients in the five pivotal trials. Data from the five pivotal trials were pooled for additional analyses, both across all five studies $(n=2,119)$ and across the three $\mathrm{CD}$ studies $(n=1,389)$ or 2 UC $(n=730)$ studies due to similarities in study design and homogeneity of the patient populations. In the 5 pivotal IBD trials, 406 and 1,713 patients were treated with placebo and infliximab, respectively (Table 3). Among the 2,117 patients with documentation of immunomodulator use at baseline (yes/no), 947 patients did and 1,170 patients did not receive the immunomodulators AZA, 6-MP, or MTX (Tables 3 and 5).

The extent of exposure to individual study agents for each of the pivotal phase 3 trials is summarized in Table 2, which includes infliximab infusions received during the main studies, as well as the blinded study extensions of SONIC and ACT 2. Excluding patients who initially received infliximab but who were later randomized to placebo maintenance treatment, $C D$ patients received an average of 6.1-7.5 infliximab infusions and UC patients received an average of 6.3-6.5 infliximab infusions. Note that study agent administration in the SONIC and ACT 2 main studies ended with the week- 22 infusion and that safety data from week 30 through week 54 were collected as part of a blinded study extension, during which patients continued to receive blinded study agent. 


\section{Infections}

The incidences of infections and serious infections were determined across the five pivotal phase 3 IBD trials. A larger proportion of infliximab- than placebo-treated UC patients $(50.1 \%$ vs. 36.3\%; $P<0.001$ ) had at least one infection. Among CD patients, however, the proportions of patients who experienced at least one infection were similar between the infliximab- and placebotreated patients $(49.1 \%$ vs. $45.3 \% ; P=0.402)$. The proportions of patients who experienced at least one serious infection were also similar between placebo- and infliximab-treated patients (Table 3). When expressed on the basis of length of patient follow-up, the incidences (95\% CIs) per $100 \mathrm{pt}$-yrs of infections were $132.81(112.00,156.36)$ in placebo- vs. $119.98(113.67,126.56)$ in infliximab-treated CD patients; $106.98(93.43,121.94)$ in placebovs. $105.41(98.54,112.63)$ in infliximab-treated UC patients; and $115.79(104.26,128.25)$ in placebo- vs. $113.80(109.12,118.62)$ in infliximab-treated IBD patients. Similar patterns of overlapping 95\% CIs between the placebo and infliximab groups were also observed for serious infections (Table 3).

When assessed by the patient's baseline immunomodulator treatment (yes/no), the $95 \%$ CIs surrounding the incidences of infections and serious infections overlapped between patients treated with immunomodulators and those not treated with immunomodulators in all patient populations (CD, UC, all IBD), with one exception. In patients with UC, but not CD, immunomodulator treatment (vs. no treatment) yielded a higher incidence $(95 \%$ CI) of infections $(120.07(110.66,130.08) / 100$ pt-yrs vs. 92.47 (84.54, 100.94)/100 pt-yrs) (Table 3).

A summary of the incidences of serious infections (per $100 \mathrm{pt}$-yrs of follow-up) by system-organ class and preferred term is also provided in Table 3. The most common serious infections were those considered resistance mechanism disorders (3.15 and 3.32/100 ptyrs in placebo- and infliximab-treated IBD patients, respectively), gastrointestinal disorders ( 0.63 and $1.07 / 100 \mathrm{pt}-\mathrm{yrs})$, and respiratory system disorders (0.94 and 0.97/100 pt-yrs). Within these three system-organ classes, the most common serious infections were abscess (1.57 and 1.89/100 pt-yrs in placebo- and infliximab-treated IBD patients, respectively), gastroenteritis (0.63 and $0.26 / 100$ pt-yrs), and pneumonia (0.31 and 0.66/100 pt-yrs) (Table 3).

\section{Malignancy}

Across the $10 \mathrm{IBD}$ trials and excluding nonmelanoma skin cancers, 13 patients (two placebo-treated, 11 infliximab-treated) had a malignancy during study participation. Of the malignancies, 11 were non-lymphoma, while two patients had lymphoma. Both patients with lymphoma were infliximab-treated CD patients. One patient who received infliximab $5 \mathrm{mg} / \mathrm{kg}$ at week 0 followed by placebo maintenance and AZA had natural killer cell lymphoma diagnosed after study participation ended. A second patient with a history of AZA use received a single infusion of infliximab $10 \mathrm{mg} /$ $\mathrm{kg}$ and was diagnosed with intravascular B-cell lymphoma 9.5 months after the single infliximab infusion. The non-lymphoma malignancies included breast $(n=2)$, colon $(n=2)$, prostate $(n=2)$, bladder $(n=1)$, lung $(n=1)$, renal $(n=1)$, skin $(n=1)$, and rectal $(n=1)$ cancers ( 9 infliximab-treated, 2 placebo).

When expressed on the basis of incidence (95\% CI) per 100 pt-yrs of follow-up, overlapping 95\% CIs indicated that the incidences of malignancies were similar in the placebo- and infliximab-treated patients with $\mathrm{CD}(1.61(0.19,5.82)$ vs. 0.49 $(0.18,1.06)$, respectively) and with UC $(0.00(0.00,1.43)$ vs. $0.60(0.20,1.40)$, respectively). Findings observed within the lymphoma and non-lymphoma malignancy subcategories were similar (Table 4).

The incidences of malignancies during only the controlled portions of the 10 IBD trials were also determined. Four patients, two placebo-treated and two infliximab-treated, had a malignancy during the controlled study phases. No cases of lymphoma were documented during the controlled portions of the 10 IBD studies.

Table 2. Extent of exposure to infliximab in the pivotal phase 3 IBD trials through week 46

\begin{tabular}{|c|c|c|c|c|c|c|c|c|c|c|c|c|c|c|}
\hline & \multicolumn{8}{|c|}{ Crohn's disease } & \multicolumn{6}{|c|}{ Ulcerative colitis } \\
\hline & \multicolumn{3}{|c|}{ ACCENT I } & \multicolumn{2}{|c|}{ ACCENT II } & \multicolumn{3}{|c|}{ SONIC } & \multicolumn{3}{|c|}{ ACT 1} & \multicolumn{3}{|c|}{ ACT 2} \\
\hline & $\mathrm{PBO}^{\mathrm{a}}$ & $\begin{array}{c}\text { INF } \\
5 \mathrm{mg} / \mathrm{kg}\end{array}$ & $\begin{array}{c}\text { INF } \\
10 \mathrm{mg} / \mathrm{kg}\end{array}$ & $\mathrm{PBO}^{\mathrm{b}}$ & $\begin{array}{c}\text { INF } \\
5 \mathrm{mg} / \mathrm{kg}\end{array}$ & $\begin{array}{c}\mathrm{AZA+} \\
\mathrm{PBO}\end{array}$ & $\begin{array}{c}\text { INF } \\
5 \mathrm{mg} / \mathrm{kg}+ \\
\mathrm{PBO}^{\mathrm{c}}\end{array}$ & $\begin{array}{c}\text { INF } \\
5 \mathrm{mg} / \mathrm{kg}+ \\
\mathrm{AZA}^{\mathrm{c}}\end{array}$ & PBO & $\begin{array}{c}\text { INF } \\
5 \mathrm{mg} / \mathrm{kg}\end{array}$ & $\begin{array}{c}\text { INF } \\
10 \mathrm{mg} / \mathrm{kg}\end{array}$ & $\mathrm{PBO}^{\mathrm{c}}$ & $\begin{array}{c}\text { INF } \\
5 \mathrm{mg} / \mathrm{kg}^{\mathrm{c}}\end{array}$ & $\begin{array}{c}\text { INF } \\
10 \mathrm{mg} / \mathrm{kg}^{\mathrm{c}}\end{array}$ \\
\hline $\begin{array}{l}\text { Pts. } \\
\text { treated }\end{array}$ & 188 & 192 & 193 & 143 & 139 & 161 & 163 & 179 & 121 & 121 & 122 & 123 & 121 & 120 \\
\hline $\begin{array}{l}\text { Average } \\
\text { no. of } \\
\text { infliximab } \\
\text { infusions }\end{array}$ & 2.2 & 6.7 & 6.8 & 4.3 & 7.5 & 0.0 & 6.1 & 6.1 & 0.0 & 6.5 & 6.3 & 0.0 & 6.4 & 6.4 \\
\hline $\begin{array}{l}\text { AZA, azathi } \\
\text { PBO, place } \\
\text { aln ACCENT } \\
\text { bIn ACCENT } \\
\text { infusions of } \\
\text { Including i }\end{array}$ & $\begin{array}{l}\text { prine; IB } \\
\text { o capsul } \\
1 \text {, place } \\
\text { II, place } \\
\text { nfliximał } \\
\text { fliximab }\end{array}$ & $\begin{array}{l}\text { D, inflamm } \\
\text { es. } \\
\text { oo patients } \\
\text { bo patients } \\
5 \mathrm{mg} / \mathrm{kg} \text {. }\end{array}$ & $\begin{array}{l}\text { atory bowel c } \\
\text { received } 5 \mathrm{~m} \\
\text { received } 5 \mathrm{~m} \\
\text { ceived durin }\end{array}$ & $\begin{array}{l}\text { lisease; II } \\
\text { g/kg inflix } \\
\text { g/kg inflix }\end{array}$ & $\begin{array}{l}\text { VF, inflixim } \\
\text { imab at we } \\
\text { imab at we }\end{array}$ & $\begin{array}{l}\text { ab; pts., } p \\
\text { ek } 0 \text {, and } \\
\text { eks } 0,2 \text {, }\end{array}$ & $\begin{array}{l}\text { atients; PBO, } \\
\text { some of them } \\
\text { and } 6 \text { before }\end{array}$ & $\begin{array}{l}\text { olacebo infus } \\
\text { also receivec } \\
\text { andomization }\end{array}$ & $\begin{array}{l}\text { ons, ex } \\
\text { episoc } \\
\text { at wee }\end{array}$ & $\begin{array}{l}\text { infust for the } \\
14 \text {, and so }\end{array}$ & $\begin{array}{l}\mathrm{JF}+\mathrm{PBO} \mathrm{gr} \\
\text { infliximab } \\
\text { e of them }\end{array}$ & $\begin{array}{l}\text { up in SC } \\
\mathrm{mg} / \mathrm{kg} \text {. } \\
\mathrm{o} \text { cross }\end{array}$ & $\begin{array}{l}\text { NIC, in whic } \\
\text { d over to re }\end{array}$ & $\begin{array}{l}\text { case: } \\
\text { eive }\end{array}$ \\
\hline
\end{tabular}


Table 3. Summary of infections and serious infections through week 54 of the pivotal phase 3 infliximab IBD studies by treatment and immunomodulator use

\begin{tabular}{|c|c|c|c|c|c|c|}
\hline & \multicolumn{2}{|c|}{ Crohn's disease $^{a}$} & \multicolumn{2}{|c|}{ Ulcerative colitis ${ }^{\mathrm{a}}$} & \multicolumn{2}{|c|}{ All inflammatory bowel disease ${ }^{a}$} \\
\hline Pts. treated & 161 & 1,228 & 245 & 485 & 406 & 1,713 \\
\hline $\begin{array}{l}\text { Total/median pt-yrs of } \\
\text { follow-up }\end{array}$ & 108/0.7 & $1,127 / 1.0$ & 209/0.6 & $831 / 1.0$ & 318/0.6 & $1,958 / 1.0$ \\
\hline No. (\%) of pts. with infection & $73(45.3 \%)$ & $603(49.1 \%)$ & $89(36.3 \%)$ & $243(50.1 \%)$ & $162(39.9 \%)$ & $846(49.4 \%)$ \\
\hline Total incidence & 144 & 1,352 & 224 & 876 & 368 & 2,228 \\
\hline Incidence per 100 pt-yrs & 132.81 & 119.98 & 106.98 & 105.41 & 115.79 & 113.8 \\
\hline $95 \% \mathrm{Cl}^{d}$ & $(112.00,156.36)$ & $(113.67,126.56)$ & $(93.43,121.94)$ & $(98.54,112.63)$ & $(104.26,128.25)$ & $(109.12,118.62)$ \\
\hline $\begin{array}{l}\text { No. (\%) of pts. with serious } \\
\text { infection }\end{array}$ & $9(5.6 \%)$ & $55(4.5 \%)$ & $6(2.4 \%)$ & $26(5.4 \%)$ & $15(3.7 \%)$ & $81(4.7 \%)$ \\
\hline $95 \% \mathrm{Cl}$ & $(3.80,15.76)$ & $(6.10,9.43)$ & $(1.05,6.24)$ & $(3.64,6.83)$ & $(2.64,7.78)$ & $(5.45,7.77)$ \\
\hline
\end{tabular}

System-organ class/common preferred terms (>0.20/per 100 pt-yrs per group)

\begin{tabular}{|c|c|c|c|c|c|c|}
\hline $\begin{array}{l}\text { Resistance mechanism } \\
\text { disorder }\end{array}$ & 5.53 & 4.44 & 1.91 & 1.8 & 3.15 & 3.32 \\
\hline Abscess & 2.77 & 3.02 & 0.96 & 0.36 & 1.57 & 1.89 \\
\hline Fever & 0 & 0.27 & 0 & 0.24 & 0 & 0.26 \\
\hline Infection & 0 & 0.18 & 0.48 & 0.84 & 0.31 & 0.46 \\
\hline Sepsis & 0.92 & 0.27 & 0 & 0.12 & 0.31 & 0.2 \\
\hline Cellulitis & 0 & 0.27 & 0 & 0 & 0 & 0.15 \\
\hline Herpes zoster & 0 & 0.27 & 0 & 0 & 0 & 0.15 \\
\hline Bacterial infection & 1.84 & 0.09 & 0.48 & 0 & 0.94 & 0.05 \\
\hline $\begin{array}{l}\text { Gastrointestinal system } \\
\text { disorder }\end{array}$ & 1.84 & 1.24 & 0 & 0.84 & 0.63 & 1.07 \\
\hline Gastroenteritis & 1.84 & 0.18 & 0 & 0.36 & 0.63 & 0.26 \\
\hline Abdominal pain & 0 & 0.27 & 0 & 0 & 0 & 0.15 \\
\hline Respiratory system disorder & 0.92 & 0.44 & 0.96 & 1.68 & 0.94 & 0.97 \\
\hline Pneumonia & 0.92 & 0.44 & 0 & 0.96 & 0.31 & 0.66 \\
\hline Sinusitis & 0 & 0 & 0.48 & 0.12 & 0.31 & 0.05 \\
\hline $\begin{array}{l}\text { Upper respiratory } \\
\text { infection }\end{array}$ & 0 & 0 & 0.48 & 0 & 0.31 & 0 \\
\hline $\begin{array}{l}\text { Skin and appendages } \\
\text { disorder }\end{array}$ & 0 & 0.53 & 0 & 0 & 0 & 0.31 \\
\hline Urinary system disorder & 0 & 0.18 & 0 & 0.24 & 0 & 0.2 \\
\hline $\begin{array}{l}\text { Body as a whole-general } \\
\text { disorder }\end{array}$ & 0 & 0.18 & 0 & 0 & 0 & 0.1 \\
\hline Cardiovascular disorder & 0 & 0.18 & 0 & 0 & 0 & 0.1 \\
\hline $\begin{array}{l}\text { Liver and biliary system } \\
\text { disorder }\end{array}$ & 0 & 0.09 & 0 & 0.12 & 0 & 0.1 \\
\hline $\begin{array}{l}\text { Musculoskeletal system } \\
\text { disorder }\end{array}$ & 0 & 0.18 & 0 & 0 & 0 & 0.1 \\
\hline Reproductive disorder & 0 & 0.09 & 0 & 0.12 & 0 & 0.1 \\
\hline
\end{tabular}




\begin{tabular}{|c|c|c|c|c|c|c|}
\hline Ear and hearing disorder & 0 & 0 & 0 & 0.12 & 0 & 0.05 \\
\hline \multirow{2}{*}{$\begin{array}{l}\text { Myo-, endo-, pericardial, } \\
\text { coronary and valve disorder }\end{array}$} & 0 & 0 & 0 & 0.12 & 0 & 0.05 \\
\hline & $\begin{array}{l}\text { No immuno- } \\
\text { modulator }\end{array}$ & $\begin{array}{l}\text { Immuno } \\
\text { modulator }\end{array}$ & $\begin{array}{l}\text { No immuno- } \\
\text { modulator }\end{array}$ & $\begin{array}{l}\text { Immuno- } \\
\text { modulator }\end{array}$ & $\begin{array}{l}\text { No immuno- } \\
\text { modulator }\end{array}$ & $\begin{array}{l}\text { Immuno- } \\
\text { modulator }\end{array}$ \\
\hline $\begin{array}{l}\text { Total/median pt-yrs of } \\
\text { follow-up }\end{array}$ & $715 / 1.0$ & $520 / 1.0$ & $541 / 0.8$ & $500 / 1.0$ & $1,256 / 1.0$ & $1,020 / 1.0$ \\
\hline $\begin{array}{l}\text { Number (\%) of pts. with } \\
\text { infection }\end{array}$ & $397(51.2 \%)$ & $279(45.5 \%)$ & 169 (42.9\%) & $163(48.8 \%)$ & $566(48.4 \%)$ & $442(46.7 \%)$ \\
\hline$P$-value & \multicolumn{2}{|c|}{0.04} & \multicolumn{2}{|c|}{0.117} & \multicolumn{2}{|c|}{0.457} \\
\hline $95 \% \mathrm{Cl}$ & $(120.24,137.00)$ & $(102.20,120.51)$ & $(84.54,100.94)$ & $(110.66,130.08)$ & $(107.13,118.97)$ & $(108.98,122.27)$ \\
\hline $\begin{array}{l}\text { Number (\%) of pts. with } \\
\text { serious infections }\end{array}$ & $36(4.6 \%)$ & $28(4.6 \%)$ & $14(3.6 \%)$ & $18(5.4 \%)$ & $50(4.3 \%)$ & $46(4.9 \%)$ \\
\hline$P$-value & \multicolumn{2}{|c|}{1} & \multicolumn{2}{|c|}{0.277} & \multicolumn{2}{|c|}{0.53} \\
\hline Total incidence & 63 & 32 & 18 & 30 & 81 & 62 \\
\hline Incidence per 100 pt-yrs & 8.81 & 6.15 & 3.33 & 6 & 6.45 & 6.08 \\
\hline $95 \% \mathrm{Cl}$ & $(6.77,11.28)$ & $(4.21,8.68)$ & $(1.97,5.26)$ & $(4.05,8.57)$ & $(5.12,8.02)$ & $(4.66,7.79)$ \\
\hline \multicolumn{7}{|c|}{$\begin{array}{l}\text { 'P-values comparing treatment or immunomodulator use subgroups were calculated with the use of Fisher's exact test. } \\
\text { d95\% Cls based on an exact method. } \\
\text { eNo receipt of AZA, 6-MP, or MTX at baseline. } \\
\text { 'Receipt of AZA, 6-MP, or MTX at baseline. }\end{array}$} \\
\hline
\end{tabular}

When comparing the proportions of patients who had malignancy diagnosed during the studies (both overall and during the controlled portions), results of Fisher's exact testing indicated no significant difference between infliximab- and placebo-treated patients (Table 4).

Further, when expressed as incidence (95\% CI) per 100 pt-yrs of follow-up, the incidences of malignancy appeared similar in placebo- vs. infliximab-treated patients with $\mathrm{CD}(1.65(0.20,5.97)$ vs. $0.00(0.00,1.00)$, respectively) and UC $(0.00(0.00,2.18)$ vs. $0.60(0.07$, $2.17)$, respectively). Consistent findings were observed within the lymphoma and non-lymphoma malignancy subcategories (Table 4).

The incidence of malignancy was also assessed by immunomodulator use in the controlled portions of the five pivotal phase 3 IBD trials. When comparing the proportions of patients who had malignancy diagnosed during the studies (both overall and during the controlled portions), results of Fisher's exact testing indicated no significant difference between infliximab- and placebo-treated patients or between patients with and without immunomodulator use (Table 4).
Further, in all three of the patient populations (CD, UC, and all IBD), the 95\% CIs surrounding the incidences of malignancy overlapped when compared between patients who were treated vs. those who were not treated with immunomodulators, with one exception. Among placebo-treated patients with $\mathrm{CD}$, but not UC, those with immunomodulator use demonstrated a higher incidence $(95 \% \mathrm{CI})$ of malignancy vs. no immunomodulator treatment $(1.84(0.22,6.66) / 100$ pt-yrs vs. $0.00(0.00,0.00) /$ $100 \mathrm{pt}-\mathrm{yrs})$.

In a separate analysis comparing the observed incidences of malignancy with rates expected in the general US population based on the SEER database, all 95\% CIs surrounding the malignancy SIRs contained 1 in all analysis groups (i.e., placebo and infliximab, with and without baseline immunomodulator use). This indicates that the incidences of malignancy observed in the controlled portions of the pivotal phase 3 trials are not significantly different from the expected rates in the general US population. Similar findings were observed within the lymphoma and non-lymphoma malignancy subcategories (Table 4). 
Table 4. Summary of malignancies (excluding nonmelanoma skin cancers) by treatment both overall and during the main portions of all infliximab IBD studies ${ }^{a}$ and by immunomodulator use during the controlled portions of the pivotal phase 3 IBD trials ${ }^{b}$

\begin{tabular}{|c|c|c|c|c|c|c|}
\hline & \multicolumn{2}{|c|}{ Crohn's disease } & \multicolumn{2}{|c|}{ Ulcerative colitis } & \multicolumn{2}{|c|}{ All inflammatory bowel disease } \\
\hline \multicolumn{7}{|c|}{ Overall among all infliximab IBD studies } \\
\hline Total/median pt-yrs of follow-up & $124 / 0.5$ & $1,229 / 1.0$ & $210 / 0.6$ & $832 / 1.0$ & $334 / 0.6$ & $2,061 / 1.0$ \\
\hline \multicolumn{7}{|l|}{ All malignancies } \\
\hline Incidence per 100 pt-yrs & 1.61 & 0.49 & 0 & 0.6 & 0.6 & 0.53 \\
\hline $95 \% \mathrm{Cl}^{\mathrm{e}}$ & $(0.19,5.82)$ & $(0.18,1.06)$ & $(0.00,1.43)$ & $(0.20,1.40)$ & $(0.07,2.16)$ & $(0.27,0.95)$ \\
\hline \multicolumn{7}{|l|}{ Lymphoma } \\
\hline No. (\%) of pts. with malignancy & $0(0.0 \%)$ & $2(0.1 \%)$ & $0(0.0 \%)$ & $0(0.0 \%)$ & $0(0.0 \%)$ & $2(0.1 \%)$ \\
\hline No. (\%) of pts. with malignancy & $2(0.9 \%)$ & $4(0.3 \%)$ & $0(0.0 \%)$ & $5(1.0 \%)$ & $2(0.4 \%)$ & $9(0.5 \%)$ \\
\hline$P$-value & \multicolumn{2}{|c|}{0.182} & \multicolumn{2}{|c|}{0.175} & \multicolumn{2}{|c|}{1} \\
\hline Incidence per 100 pt-yrs & 1.61 & 0.33 & 0 & 0.6 & 0.6 & 0.44 \\
\hline $95 \% \mathrm{Cl}$ & $(0.19,5.82)$ & $(0.09,0.83)$ & $(0.00,1.43)$ & $(0.20,1.40)$ & $(0.07,2.16)$ & $(0.20,0.83)$ \\
\hline \multicolumn{7}{|c|}{ Controlled portions of all infliximab IBD studies } \\
\hline Pts. treated & 217 & 488 & 245 & 483 & 462 & 971 \\
\hline Total/median pt-yrs of follow-up & $121 / 0.5$ & 298/0.6 & $137 / 0.6$ & $333 / 0.6$ & $258 / 0.6$ & $631 / 0.6$ \\
\hline \multicolumn{7}{|l|}{ All malignancies } \\
\hline No. (\%) of pts. with malignancy & $2(0.9 \%)$ & $0(0.0 \%)$ & $0(0.0 \%)$ & $2(0.4 \%)$ & $2(0.4 \%)$ & $2(0.2 \%)$ \\
\hline Non-lymphoma malignancies & & & & & & \\
\hline No. (\%) of pts. with malignancy & $2(0.9 \%)$ & $0(0.0 \%)$ & $0(0.0 \%)$ & $2(0.4 \%)$ & $2(0.4 \%)$ & $2(0.2 \%)$ \\
\hline$P$-value & & & & & & \\
\hline Incidence per 100 pt-yrs & 1.65 & 0 & 0 & 0.6 & 0.77 & 0.32 \\
\hline $95 \% \mathrm{Cl}$ & $(0.20,5.97)$ & $(0.00,1.00)$ & $(0.00,2.18)$ & $(0.07,2.17)$ & $(0.09,2.80)$ & $(0.04,1.15)$ \\
\hline & $\begin{array}{l}\text { No immuno- } \\
\text { modulator }\end{array}$ & $\begin{array}{l}\text { Immuno } \\
\text { modulator }^{\text {g }}\end{array}$ & $\begin{array}{l}\text { No immuno- } \\
\text { modulator }\end{array}$ & $\begin{array}{l}\text { Immuno } \\
\text { modulator }\end{array}$ & $\begin{array}{l}\text { No immuno- } \\
\text { modulator }^{f}\end{array}$ & $\begin{array}{l}\text { Immuno- } \\
\text { modulator }^{g}\end{array}$ \\
\hline Controlled portions of 5 pivotal IBD & & & & & & \\
\hline Pts. treated & 166 & 337 & 394 & 334 & 560 & 671 \\
\hline All malignancies & & & & & & \\
\hline Total/median pt-yrs of follow-up & $129 / 1.0$ & $250 / 0.9$ & $250 / 0.6$ & $220 / 0.6$ & $378 / 0.6$ & $470 / 0.7$ \\
\hline No. (\%) of pts. with malignancy & $0(0.0 \%)$ & $2(0.6 \%)$ & $1(0.3 \%)$ & $1(0.3 \%)$ & $1(0.2 \%)$ & $3(0.5 \%)$ \\
\hline$P$-value & & & & & & \\
\hline Incidence per 100 pt-yrs & 0 & 0.8 & 0.4 & 0.45 & 0.26 & 0.64 \\
\hline $95 \% \mathrm{Cl}$ & $(0.00,2.33)$ & $(0.10,2.89)$ & $(0.01,2.23)$ & $(0.01,2.53)$ & $(0.01,1.47)$ & $(0.13,1.87)$ \\
\hline Expected no. of pts. ${ }^{\mathrm{h}}$ & 0.43 & 0.71 & 1.22 & 0.88 & 1.65 & 1.6 \\
\hline SIRi & 0 & 2.8 & 0.82 & 1.13 & 0.61 & 1.88 \\
\hline SIR 95\% Cl & $(0.00,6.92)$ & $(0.34,10.11)$ & $(0.02,4.58)$ & $(0.03,6.30)$ & $(0.02,3.38)$ & $(0.39,5.48)$ \\
\hline
\end{tabular}


Table 4. Continued

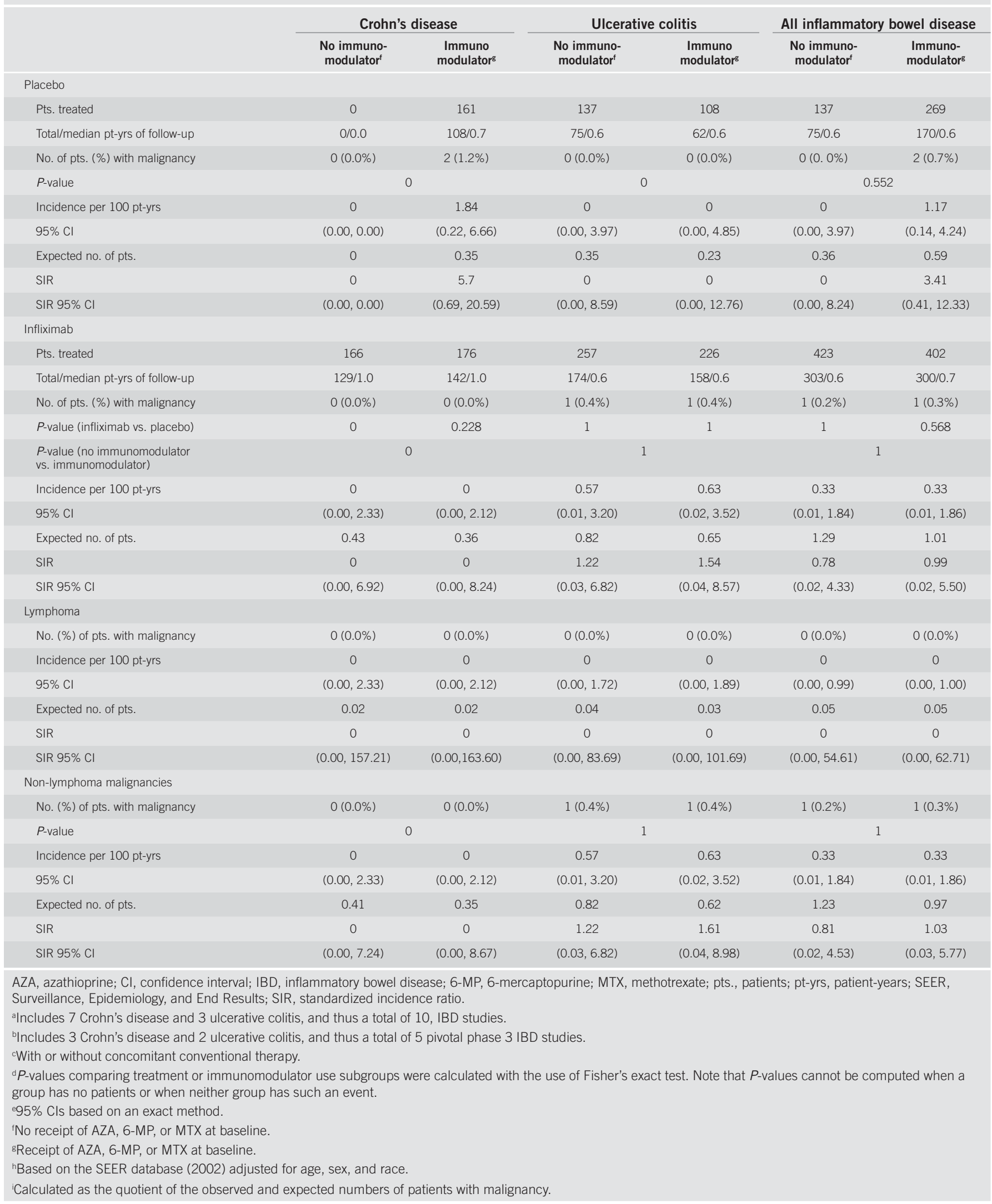


Table 5. Summary of mortality through week 54 by treatment (all IBD studies) and immunomodulator use status (pivotal phase 3 IBD trials)

\begin{tabular}{|c|c|c|c|c|c|c|}
\hline & \multicolumn{2}{|c|}{ Crohn's disease $^{a}$} & \multicolumn{2}{|c|}{ Ulcerative colitis ${ }^{a}$} & \multicolumn{2}{|c|}{ All inflammatory bowel disease ${ }^{a}$} \\
\hline Pts. treated & 217 & 1,427 & 248 & 493 & 465 & 1,920 \\
\hline $\begin{array}{l}\text { Total/median pt-yrs of } \\
\text { follow-up }\end{array}$ & $124 / 0.5$ & $1,230 / 1.0$ & 210/0.6 & 833/1.0 & 334/0.6 & $2,063 / 1.0$ \\
\hline \multicolumn{7}{|l|}{ Deaths } \\
\hline$P$-value ${ }^{c}$ & \multicolumn{2}{|c|}{0.433} & \multicolumn{2}{|c|}{1} & \multicolumn{2}{|c|}{1} \\
\hline Incidence/100 pt-yrs & 0.8 & 0.24 & 0 & 0.12 & 0.3 & 0.19 \\
\hline $95 \% \mathrm{Cl}^{d}$ & $(0.02,4.48)$ & $(0.05,0.71)$ & $(0.00,1.43)$ & $(0.00,0.67)$ & $(0.01,1.67)$ & $(0.05,0.50)$ \\
\hline \multicolumn{7}{|l|}{ Infection-related deaths } \\
\hline \multirow[t]{2}{*}{$95 \% \mathrm{Cl}$} & $(0.02,4.48)$ & $(0.02,0.59)$ & $(0.00,1.43)$ & $(0.00,0.67)$ & $(0.01,1.67)$ & $(0.03,0.43)$ \\
\hline & $\begin{array}{l}\text { No immuno- } \\
\text { modulator }^{\mathrm{e}}\end{array}$ & $\begin{array}{l}\text { Immuno- } \\
\text { modulator }\end{array}$ & $\begin{array}{l}\text { No immuno- } \\
\text { modulator }^{\mathrm{e}}\end{array}$ & $\begin{array}{l}\text { Immuno- } \\
\text { modulatorf }\end{array}$ & $\begin{array}{l}\text { No immuno- } \\
\text { modulator }^{\mathrm{e}}\end{array}$ & $\begin{array}{l}\text { Immuno- } \\
\text { modulator }\end{array}$ \\
\hline Pts. treated & 776 & 613 & 394 & 334 & 1,170 & 947 \\
\hline $\begin{array}{l}\text { Total/median pt-yrs of } \\
\text { follow-up }\end{array}$ & $715 / 1.0$ & $520 / 1.0$ & $541 / 0.8$ & $500 / 1.0$ & $1,256 / 1.0$ & $1,020 / 1.0$ \\
\hline \multicolumn{7}{|l|}{ Deaths } \\
\hline No. (\%) of pts. & $2(0.3 \%)$ & $2(0.3 \%)$ & $0(0.0 \%)$ & $1(0.3 \%)$ & $2(0.2 \%)$ & $3(0.3 \%)$ \\
\hline$P$-value & \multicolumn{2}{|c|}{1} & \multicolumn{2}{|c|}{0.459} & \multicolumn{2}{|c|}{0.662} \\
\hline
\end{tabular}

In addition to the malignancies discussed above, among the 2,385 patients with IBD included in these analyses (465 placebo, 1,920 infliximab), five patients (3 infliximab-treated, 2 placebo-treated) had basal cell carcinoma and two patients (both infliximab-treated) had malignant skin neoplasm.

\section{Mortality}

Five patients died during the 10 IBD trials. The deaths included a patient (63-year-old female with baseline immunomodulator use) with CD in SONIC who received AZA monotherapy and died of sepsis following a colectomy; three infliximabtreated patients with CD in ACCENT I who died of septic shock (35-year-old female with no baseline immunomodulator use), sepsis (57-year-old female with no baseline immunomodulator use), and myocardial infarction (37-year-old male with baseline immunomodulator use); and one infliximab-treated patient with UC in ACT 2 (56-year-old male with baseline immunomodulator use) who died following diagnosis of pulmonary histoplasmosis during the open-label, long-term, follow-up period.

Given the longer follow-up periods for infliximab-treated patients, when summarized as incidence (95\% CI) per 100 pt-yrs of follow-up, overlapping CIs indicated no increase in mortality with infliximab vs. placebo treatment among patients with $\mathrm{CD}(0.24(0.05,0.71)$ vs. $0.80(0.02,4.48)$, respectively), UC $(0.12(0.00,0.67)$ vs. $0.00(0.00$, $1.43)$, respectively), or $\operatorname{IBD}(0.19(0.05,0.50)$ vs. $0.30(0.01,1.67)$, respectively). The same was true for infection-related deaths, which 
accounted for four of the five deaths. Overlapping 95\% CIs were also observed in a separate analysis of mortality by immunomodulator use in the five pivotal phase 3 IBD trials (Table 5).

\section{DISCUSSION}

Since receiving marketing authorization for the treatment of CD more than a decade ago, infliximab has gained wide acceptance as a highly effective treatment option for IBD. As a result, longer-term safety data are becoming available. No difference in the incidence of neoplasia between adult patients with CD who were $(n=404)$ and were not $(n=404)$ treated with infliximab was reported by Biancone et al (17). An additional 4 years of follow-up of 591 of the patients in this matched-pair study yielded consistent findings, with 3.9\% (12/304) of infliximabtreated patients and $4.2 \%(12 / 287)$ of patients not treated with infliximab diagnosed with neoplasia $(P=0.95)(18)$. Fidder et al. (19), who retrospectively examined medical records of 734 infliximab-treated IBD patients and 666 controls, also observed no difference between the two groups in mortality, malignancy including lymphoma, or infection rate. In a retrospective safety analysis of 799 German IBD patients treated with thiopurines and/or TNF antagonists between 2002 and 2010, an elevated risk of malignancy $(4.2 \%$ vs. $1.5 \%, P=0.024$, odds ratio $=2.86)$, but not infection $(14.4 \%$ vs. $15.5 \%, P=0.69)$, was observed in patients treated with only thiopurines relative to patients treated with TNF antagonists with or without thiopurines (20). Results of several large randomized phase 3 clinical trials of infliximab maintenance therapy in IBD, including the ACCENT I $(5,6)$, ACCENT II (7), and SONIC (8) trials in CD and the ACT 1 and ACT 2 trials (9) in UC also contribute to the growing body of infliximab safety data.

Findings presented herein from a pooled analysis of key safety outcomes, derived from 10 sponsor-conducted IBD studies with large cohorts of IBD patients treated by referral centers in daily practice, are generally consistent with conclusions drawn by Biancone et al. $(17,18)$ and Fidder et al. (19). Specifically, results of our pooled analyses of infliximab safety data in the treatment of IBD indicate no increase in infections or serious infections with infliximab vs. placebo treatment in patients with CD or UC. Independent of infliximab use, immunomodulator treatment did not appear to increase the incidence of infections or serious infections in patients with CD but did yield a higher incidence of infection vs. no immunomodulator treatment in patients with UC. One explanation for the lack of an increase in the incidence of serious infections with either infliximab or immunomodulators in $\mathrm{CD}$ is that many of the complications of CD are inherently infectious in nature and may be decreased by effective CD therapy. Results derived from the TREAT Registry of CD patients, which included assessment of the role of corticosteroids in infectious complications, have shown that infliximab allows for steroid tapering and discontinuation in CD (21). Several of the protocols for the pivotal phase 3 trials included in this report mandated steroid tapering during the early phase of the trial. The lower steroid consumption in the reported CD trials may also contribute to the relatively low incidence of serious infections, regardless of immunomodulator use, as such an effect could offset any small increase in serious infections that might be associated with the immunosuppressive nature of these drugs. These findings are also consistent with additional data from the TREAT Registry that indicated that the risk for serious infection in infliximabtreated CD patients is similar to that for patients receiving conventional immunomodulators (21). Despite our observation of no increase in serious infections, all patients should be screened for pre-existing infections before the start of any immunosuppressive therapy.

Overall, 13 patients ( 2 placebo-treated, 11 infliximab-treated) had a malignancy (excluding nonmelanoma skin cancer) during the 10 IBD trials, equating to incidences of 0.60 and $0.53 / 100 \mathrm{pt}-$ yrs, among placebo- and infliximab-treated IBD patients, respectively. Two of the malignancies in infliximab-treated CD patients were lymphomas; the 11 other malignancies across both cohorts were non-lymphoma.

During the controlled portions of the 10 IBD trials, four patients (2 placebo, 2 infliximab) had a malignancy, all non-lymphoma, equating to incidences of 0.77 and $0.32 / 100$ pt-yrs, respectively, of placebo- and infliximab-treated IBD patients. The incidence of malignancy was not higher with infliximab treatment, nor was it significantly impacted by immunomodulator use. In a separate analysis comparing the observed incidences of malignancy with rates expected in the general US population based on the SEER database, the incidence of malignancy was not significantly different.

A higher incidence of malignancy was observed in placebotreated patients receiving vs. those not receiving immunomodulators. These findings may support others suggesting that the thiopurines AZA and 6-MP are associated with a moderately increased risk of malignancy, particularly lymphoproliferative disease. Specifically, in a French cohort of nearly 20,000 patients with IBD (60\% with CD, $40 \%$ with UC or unclassified IBD) followed for an average of 35 months, the risk of lymphoproliferative disorder was 5 times higher in patients exposed to thiopurines than in those never exposed to these drugs. Older age, male sex, and longer duration of IBD were also associated with increased risk of lymphoproliferative disorder in the French cohort (22). Also, as noted above, results of a retrospective safety analysis of 799 German IBD patients treated with thiopurines and/or TNF antagonists between 2002 and 2010 indicated an elevated risk of malignancy $(4.2 \%$ vs. $1.5 \%, P=0.024$, odds ratio $=2.86)$ in patients treated with only thiopurines relative to patients treated with TNF antagonists with or without thiopurines (20).

We also determined malignancy SIRs within the groups of patients with and without baseline immunomodulator use. Results of these pooled analyses indicated no significant difference from the expected rates in the general US population. Conversely, recently reported results of a meta-analysis of 26 studies of infliximab, adalimumab, and certolizumab, including almost 9,000 CD patients, indicated that use of anti-TNF agents with immunomodulators is associated with an increased, albeit small (6.1/10,000 pt-yrs), risk of non-Hodgkin's lymphoma relative to 
the expected rate of non-Hodgkin's lymphoma derived from the SEER database, i.e., $1.9 / 10,000 \mathrm{pt}-\mathrm{yrs}(\mathrm{SIR}(95 \% \mathrm{CI})=3.23(1.5$, 6.9)), and also relative to the expected rate for $\mathrm{CD}$ patients treated with only immunomodulators, i.e., 4.0/10,000 pt-yrs (SIR (95\% $\mathrm{CI})=1.70(0.5,7.1))(23)$. As noted above, no cases of lymphoma were reported during the controlled portions of the trials comprising our pooled analyses. In addition to the malignancies discussed above, among the 2,385 patients with IBD included in these analyses (465 placebo, 1,920 infliximab), five patients (3 infliximab-treated, 2 placebo-treated) had basal cell carcinoma and two patients (both infliximab-treated) had nonmelanoma malignant skin neoplasm. It is still not certain whether or not infliximab use increases the risk of malignancy, but it is possible that the impact of infliximab is no worse than that of conventional immunomodulators and that, by effectively controlling inflammation, infliximab may contribute to a lower malignancy risk in IBD. The latter possibility requires further confirmation with longer-term data.

Consistent with published reports citing no evidence of increased mortality in $\mathrm{CD}$ patients treated with anti-TNF agents $(19,20,24)$, we observed no difference in mortality between placebo- and infliximab-treated patients with either $C D$ or UC. The same was true for infection-related deaths, which accounted for four of the five deaths. Immunomodulator treatment was also unassociated with increases in mortality in these IBD patients.

One point to note in the interpretation of these data is that, with the exception of the SONIC trial (8), immunomodulator treatment was not randomized, blinded, or controlled and reflects patient treatment at the time of study entry (as study protocols stipulated that any baseline immunomodulator treatment regimen would remain stable throughout study participation). It therefore remains possible that any higher event incidence in the immunomodulator-treated patients reflects their having more severe IBD rather than immunomodulator use itself. For this reason, any comparison between event rates between infliximab vs. immunomodulators must be made with caution. Still, the data of Fidder et al. (19) showed no difference in the rates of infection, malignancy including lymphoma, and mortality between IBD patients treated with infliximab and IBD patients treated with conventional therapies. It should also be noted, however, that the overall pooled results do not differ from those of the SONIC trial, in which both treatment with infliximab and treatment with immunomodulators were randomized in a controlled trial. It is also important to note that the relatively short period of follow-up, along with the relative lack of power inherent in these clinical trial data for determining treatment group differences in rare safety events, limit our ability to draw definitive conclusions from these analyses. The powering, however, is fairly good for detecting a doubling or tripling of the malignancy rate, both of which are clinically important to exclude. The 2,061 pt-yrs of follow-up from the infliximab-treated IBD cohort in this paper would yield $71 \%$ or $99 \%$ power to detect a doubling or tripling in malignancy incidence, respectively. Representing data derived from rigorous clinical trials, therefore, the current data are somewhat reassuring and have merit when assessing the overall safety of anti-TNF agents.

When taken together, results of these pooled analyses indicate no increase in serious infection, mortality, or malignancy, including lymphoma in association with infliximab treatment of IBD. In addition, the safety of infliximab in these analyses appears comparable to that of conventional immunomodulators.

\section{ACKNOWLEDGMENTS}

We thank James P. Barrett and Mary Ann Thomas of Janssen Biotech, Inc., for their work on the study protocols, Kathryn Mingione of Janssen for her work pertaining to data interpretation, and Michelle Perate and Mary H. Whitman of Janssen Biotech, Inc., for their writing support.

\section{CONFLICT OF INTEREST}

Guarantor of the article: Gary R. Lichtenstein, MD. Specific author contributions: Design and conduct of clinical trials contributing data to these pooled analyses: Gary R. Lichtenstein, Paul Rutgeerts, William J. Sandborn, Bruce E. Sands, and Robert $\mathrm{H}$. Diamond; data collection and analysis: Robert $\mathrm{H}$. Diamond, Linda Tang, Jennifer Montello, and Freddy Cornillie; and all authors provided critical content review and final approval of this manuscript.

Financial support: Funding for the clinical trials contributing data to these pooled analyses was provided by Janssen Research \& Development, a Johnson \& Johnson (J\&J) pharmaceutical company.

Potential competing interests: Dr Lichtenstein has received research grants and/or has served as a consultant for Abbott Corporation, Alaven, Bristol-Myers Squibb, Janssen, Elan, Ferring, Meda Pharmaceuticals, Merck/Schering-Plough, Millennium Pharmaceuticals, Pfizer Pharmaceuticals, Proctor and Gamble, Prometheus Laboratories, Salix Pharmaceuticals, Santarus, Shire Pharmaceuticals, UCB, Warner Chilcotte, and Wyeth. Professor Rutgeerts has received research support from Janssen, Merck/Schering-Plough, UCB, and Abbott Laboratories, as well as consulting and/or speaking honoraria from Janssen, Merck/Schering-Plough, UCB, Abbott Laboratories, Elan-Biogen, NovImmune, Italfarmako, Bristol-Myers Squibb, Millennium Pharmaceuticals, Tillots, Glaxo SmithKline, and ChemoCentryx. Dr Sandborn has received has received consulting fees and research support from Abbott Laboratories, Janssen, and UCB Pharma, as well as consulting fees from Merck/Schering-Plough. Dr Sands has received consulting fees from Abbott Immunology, Axcan Pharma, Avaxia Biologics, Bristol-Myers Squibb, Elan Pharmaceuticals, Emmi Solutions, Janssen, Glaxo Wellcome SmithKline, Millennium Pharmaceuticals/Takeda, Novartis Pharmaceuticals, Pfizer, Prometheus Laboratories, and owns common stock in Avaxia Biologics, a company that is not publicly traded. Professor Colombel has received consulting fees and has participated in continuing medical education events supported by unrestricted educational grants from Janssen and Merck/Schering-Plough. Dr Diamond and Linda Tang are employed by Janssen Research \& Development, a J\&J pharmaceutical company. Jennifer Montello is an employee of J\&J. 
Freddy Cornillie is an employee of Janssen Biologics BV, a J\&J pharmaceutical company.

\section{Study Highlights}

\section{WHAT IS CURRENT KNOWLEDGE}

The anti-tumor necrosis factor (TNF) agent infliximab has been used to treat patients with moderately-to-severely active inflammatory bowel disease for more than a decade.

Safety issues unique to TNF inhibitors, including lifethreatening and opportunistic infection, malignancy, and mortality, continue to be monitored.

\section{WHAT IS NEW HERE}

We completed a pooled analysis of key safety outcomes for all Janssen-sponsored major clinical trials of infliximab in inflammatory bowel disease (IBD).

Pooled safety data indicate no increase in serious infection, mortality, or malignancy, including lymphoma, with infliximab vs. conventional immunomodulators in the treatment of IBD.

The safety data on infliximab in a large number of IBD patients is reassuring.

\section{REFERENCES}

1. Ferkolj I. How to improve the safety of biologic therapy in Crohn's disease. J Physiol Pharmacol 2009;60 (Suppl 7): 67-70.

2. Biancone L, Tosti C, Fina D et al. Review article: maintenance treatment of Crohn's disease. Aliment Pharmacol Ther 2003;17 (Suppl 2): 31-7.

3. Patel V, MacDonald JK, MacDonald JW et al. Methotrexate for maintenance of remission in Crohn's disease. Cochrane Database Sys Rev 2009;4:CD006884.

4. Ha C, Dassopoulos T. Thiopurine therapy in inflammatory bowel disease. Expert Rev Gastroenterol Hepatol 2010;4:575-88.

5. Hanauer SB, Feagan BG, Lichtenstein GR et al. Maintenance infliximab for Crohn's disease: the ACCENT I randomised trial. Lancet 2002;359:1541-9.

6. Rutgeerts P, Feagan BG, Lichtenstein GR et al. Comparison of scheduled and episodic treatment strategies of infliximab in Crohn's disease. Gastroenterology 2004;126:402-13.

7. Sands BE, Anderson FH, Bernstein $\mathrm{CN}$ et al. Infliximab maintenance therapy for fistulizing Crohn's disease. N Engl J Med 2004;350:876-85.

8. Colombel JF, Sandborn WJ, Reinisch W et al. Infliximab, azathioprine, or combination therapy for Crohn's disease. N Engl J Med 2010;362:1383-95.

9. Rutgeerts P, Sandborn WJ, Feagan BG et al. Infliximab for induction and maintenance therapy for ulcerative colitis. N Engl J Med 2005;353:2462-76; Erratum in: N Engl J Med 2006;354:2200. Comment/author reply in: N Engl J Med 2006;354:1424-6; J Pediatr Gastroenterol Nutr 2006;42:589-90.

10. Cornillie F, Shealy D, D'Haens G et al. Infliximab induces potent antiinflammatory and local immunomodulatory activity but no systemic

immune suppression in patients with Crohn's disease. Aliment Pharmacol Ther 2001;15:463-73.

11. Present DH, Rutgeerts $P$, Targan $S$ et al. Infliximab for the treatment of fistulas in patients with Crohn's disease. N Engl J Med 1999;340:1398-405.

12. Rutgeerts P, D'Haens G, Targan S et al. Efficacy and safety of retreatment with anti-tumor necrosis factor antibody (infliximab) to maintain remission in Crohn's disease. Gastroenterology 1999;117:761-9.

13. Sands BE, Tremaine WJ, Sandborn WJ et al. Infliximab in the treatment of severe, steroid-refractory ulcerative colitis: a pilot study. Inflamm Bowel Dis 2001;7:83-8.

14. Targan SR, Hanauer SB, van Deventer SJ et al. A short-term study of chimeric monoclonal antibody cA2 to tumor necrosis factor alpha for Crohn's disease. Crohn's Disease cA2 Study Group. N Engl J Med 1997;337:1029-35.

15. van Dullemen HM, van Deventer SJ, Hommes DW et al. Treatment of Crohn's disease with anti-tumor necrosis factor chimeric monoclonal antibody (cA2). Gastroenterology 1995;109:129-35.

16. National Cancer Institute. Surveillance, Epidemiology and End Results 2002. http://seer.cancer.gov.

17. Biancone L, Orlando A, Kohn A et al. Infliximab and newly diagnosed neoplasia in Crohn's disease: a multicentre matched pair study. Gut 2006;55:228-33.

18. Biancone L, Petruzziello C, Orlando A et al. Cancer in Crohn's disease patients treated with infliximab: a long-term multicenter matched pair study. Inflamm Bowel Dis 2011;17:758-66.

19. Fidder H, Schnitzler F, Ferrante M et al. Long-term safety of infliximab for the treatment of inflammatory bowel disease: a single center cohort study. Gut 2009;58:501-8.

20. Ochsenkühn T, Steinborn A, Beigel F et al. Rate of malignancies and infections in a large single center cohort of IBD patients treated with thiopurines and anti-TNF-antibodies. Dig Dis Week 2011; May 7-10: Abstract Tu1230.

21. Lichtenstein GR, Feagan BG, Cohen RD et al. Serious infections and mortality in association with therapies for Crohn's disease: TREAT Registry. Clin Gastroenterol Hepatol 2006;4:621-30; Erratum in Clin Gastroenterol Hepatol 2006;4:931. Comment in: Inflamm Bowel Dis 2007;13:933-4.

22. Beaugerie L, Brousse N, Bouvier AM et al. for the CESAME Study Group. Lymphoproliferative disorders in patients receiving thiopurines for inflammatory bowel disease: a prospective observational cohort study. Lancet 2009;374:1617-25.

23. Siegel CA, Marden SM, Persing SM et al. Risk of lymphoma associated with combination anti-tumor necrosis factor and immunomodulator therapy for the treatment of Crohn's disease: a meta-analysis. Clin Gastroenterol Hepatol 2009;7:874-81.

24. Colombel JF, Sandborn WJ, Panaccione R et al. Adalimumab safety in global clinical trials of patients with Crohn's disease. Inflamm Bowel Dis 2009;15:1308-19.

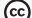

This work is licensed under the Creative Commons Attribution-NonCommercial-No Derivative Works 3.0 Unported License. To view a copy of this license, visit http://creativecommons.org/licenses/by-nc-nd/3.0/ 